Anthropol. Sci. 102(1), 59-74, 1994

\title{
The Skulls of Ubayama Shell-mounds \\ II. An Analysis of Intra- and Inter-regional Variation of the Jomon Population
}

\author{
OSAMU Kondo \\ Department of Anatomy, Sapporo Medical University, \\ South 1, West 17, Chuo-ku, Sapporo 060, Japan
}

Received November 30, 1992

\begin{abstract}
Inter-regional comparative studies of cranial morphology depend upon composite specimens constructed according to the standards chosen by the writers. Although there have been many reports about variations within the so-called "Jomon population," very few have taken up the issue of the validity of the regional classification. In this study, Mahalanobis' $D^{2} s$ are calculated from metric and nonmetric data to evaluate the intra- and inter-regional variation of Jomon crania, mainly from two regions - northern Chiba and the Atsumi Peninsula. The samples of both districts cannot be regarded as a homogeneous unit with morphological peculiarity by the $D^{2}$ s and bootstrap derived probabilities. The heterogeneities of the intra-regional variation are as large as those of inter-regional variation. This may indicate that, at least in the samples used for this study, morphological differences are not parallel to regional ones and thus, for what has been called the "Jomon population," the regional classification is not valid.
\end{abstract}

Key Words: Jomon skulls, regional variation, Mahalanobis' distance, bootstrap method

\section{INTRODUCTION}

There have been many studies on Jomon cranial variation. Suzuki (1969) investigated microevolutional changes of the Japanese population, using the Jomon cranial series from the Kanto district as a representative sample of the Jomon population, and Ogata $(1967,1973,1981)$ discussed temporal differences of the Jomon crania, which were divided into two groups of different periods - the Initial or Early Jomon and the Middle, Late or Final Jomon. Comparing specimens from shell-mounds in coastal regions with those from cave-sites in mountain regions, Ikeda (1985) suggested environmental effects on cranial morphology.

A few authors have reached similar conclusions that the Jomon population was morphologically as homogeneous as modern Japanese (Yamaguchi, 1981, 1982; Dodo, 1982). Yamaguchi investigated cranial metric variation between the Tsukumo, Yoshiko and southern Kanto Jomon series and compared it with the variation in the modern Japanese. He found a morphological cline from Tsukumo to southern Kanto in several characters. Dodo made metric comparisons of Tohoku Jomon crania with 
those from Kanto and western Honshu. He also investigated the incidence of nonmetrical characters in cranial series from the Tohoku Jomon, western Japanese Jomon and Ainu (Dodo, 1986).

In most previous studies of inter-regional Jomon cranial variation, the Jomon cranial series was divided into samples based on composite values of specimens from several geographical regions or periods; the differences between these composites were then investigated. However, the variation between archeological units, not mentioned in the previous studies, must be investigated before lumping because cranial variations with sites may exist within the combined samples. In other words, we should pay attention to the degree of homogeneity between archeological sites within each region.

Uchida (1985) discussed the morphological variation of Jomon crania among individual archeological sites. Even though she found wide variation between archeological sites within a geographical region, the low number of specimens from individual sites forestalled deeper inquiry, and she was forced in the end to pool samples from several regions for an inter-regional analysis. This study is a followup of Uchida's analysis. Using a new simulating technique called the "bootstrap" method which partially overcomes the problem of small sample sizes, I was able to include more information from the data sets into the analysis and to statistically evaluate the homogeneity within each region. The aim of the present analysis is to clarify in more detail the morphological variation of Jomon crania in view of the respective archeological units and then discuss the intra- and inter-regional homogeneity or heterogeneity of the Jomon population.

In part I of this article, I report the general morphology of the skulls of the Ubayama shell-mounds, Chiba prefecture (Kondo, 1993). From basic comparisons with other sites, some regional characteristics were found, but I could not give an interpretation of their variation mainly because of a lack of contextual information. In this paper, based on total cranial morphology, I assess the validity of samples combined from sites often used in comparative studies of the Jomon population. The Ubayama material is expected to play an important part in this respect.

\section{MATERIALS AND METHODS}

I used the cranial measurements only of Jomon males because, in females, many specimens in the comparative samples were heavily damaged and thus the available sample sizes were limited. The names of sites, the sample sizes (parentheses) and the persons responsible for the measurements of respective group are as follows:

Ubayama (26) and Kasori (9): the author

Kusakari (7): Hiramoto and Mizoguchi (1986)

Sanganji (16): the author

Yoshiko (41): Kintaka (1928) 
Ikawazu (4) and Hobi (10): the author

Tsukumo (22): Kiyono and Miyamoto (1926)

I also collected the descriptive data mentioned in part I of this article (Kondo, 1993). All the data used here were collected by myself. Available sample sizes were 58 for Ubayama, 20 for Kasori, 13 for Kusakari, 17 for Kosaku, 38 for Sanganji, 35 for Ikawazu and 35 for Hobi. Sex determination accords with that of the original reports on the respective sites (Hanihara et al., 1988; Hiramoto and Mizoguchi, 1986; Kobayashi 1966; Morimoto et al., 1983; Ogata, 1969; Suzuki et al., 1968, 1972). Some specimens not reported in the previous papers were sexed by myself based mainly on associated pelves.

With the exception of the Kosaku and Kusakari samples, all the specimens studied are stored in the University Museum, the University of Tokyo or the National Science Museum, Tokyo. The specimens from Kosaku are stored in the Department of Anatomy, St. Marianna University School of Medicine and those from Kusakari are stored in the Cultural Properties Center of Chiba Prefecture, Chiharadai Branch Office. The locations of all the archeological sites concerned here are shown in Fig. 1.

I first investigated the regional homogeneity of Jomon skulls from the northern Chiba and Atsumi Peninsula districts using the metric data of males. The components of the northern Chiba population are Ubayama, Kasori and Kusakari, and those of the Atsumi Peninsula are Yoshiko, Ikawazu and Hobi. Ten metric variables were used: maximum cranial length, maximum cranial breadth, minimum frontal breadth, auriculo-bregmatic height, sagittal frontal arc, sagittal parietal arc, outer biorbital breadth, upper facial height, orbital breadth and orbital height. These variables were selected to illustrate the general morphology of the entire cranium in as unbiased a way as possible. The choice of variables can change the distribution of the missing values and therefore, there are some limitations in the validity of this analysis.

The regional homogeneity was evaluated using the bootstrap probability of a certain sample for the reference population of the region. The bootstrap method was developed by Efron (1982), Efron and Gong (1983) and Diaconis and Efron (1983) to circumvent the limitations of the normal distribution method. The bootstrap enables the calculation of probabilities by resampling a sample randomly from the reference population to estimate the null distribution of a variable, for example, correlations between tooth crown diameter and foodstuff intakes (Mizoguchi, 1993) or a $T$-distribution of EDMA analysis (Lele and Richtsmeier, 1992). This method may partly overcome the issues of small sample sizes, which had obviated earlier analysis based on sites. Specimens with some missing values can be included in the data sets to increase the amount of information.

In addition to the metric approach, I used the Mahalanobis' $D^{2}$ equivalent for descriptive characters to assess biological distance between groups. I followed the distance equation of Konigsberg (1990), where a tetrachoric correlation matrix 
between characters is employed instead of a covariance matrix. In calculating the tetrachoric correlation, I applied an approximate equation (Yasuda, 1977). Before the calculation was done, all the descriptive data were transformed into 1-0 (all-ornone) data. The determination of a dividing point was made by splitting a sample into two groups at a position between several categories so that the numbers of specimens in the divided groups became as equivalent as possible (Mizoguchi, 1985). After calculating the $D^{2}$ equivalent, all the samples were plotted in a twodimensional plane by means of the multidimensional scaling method.

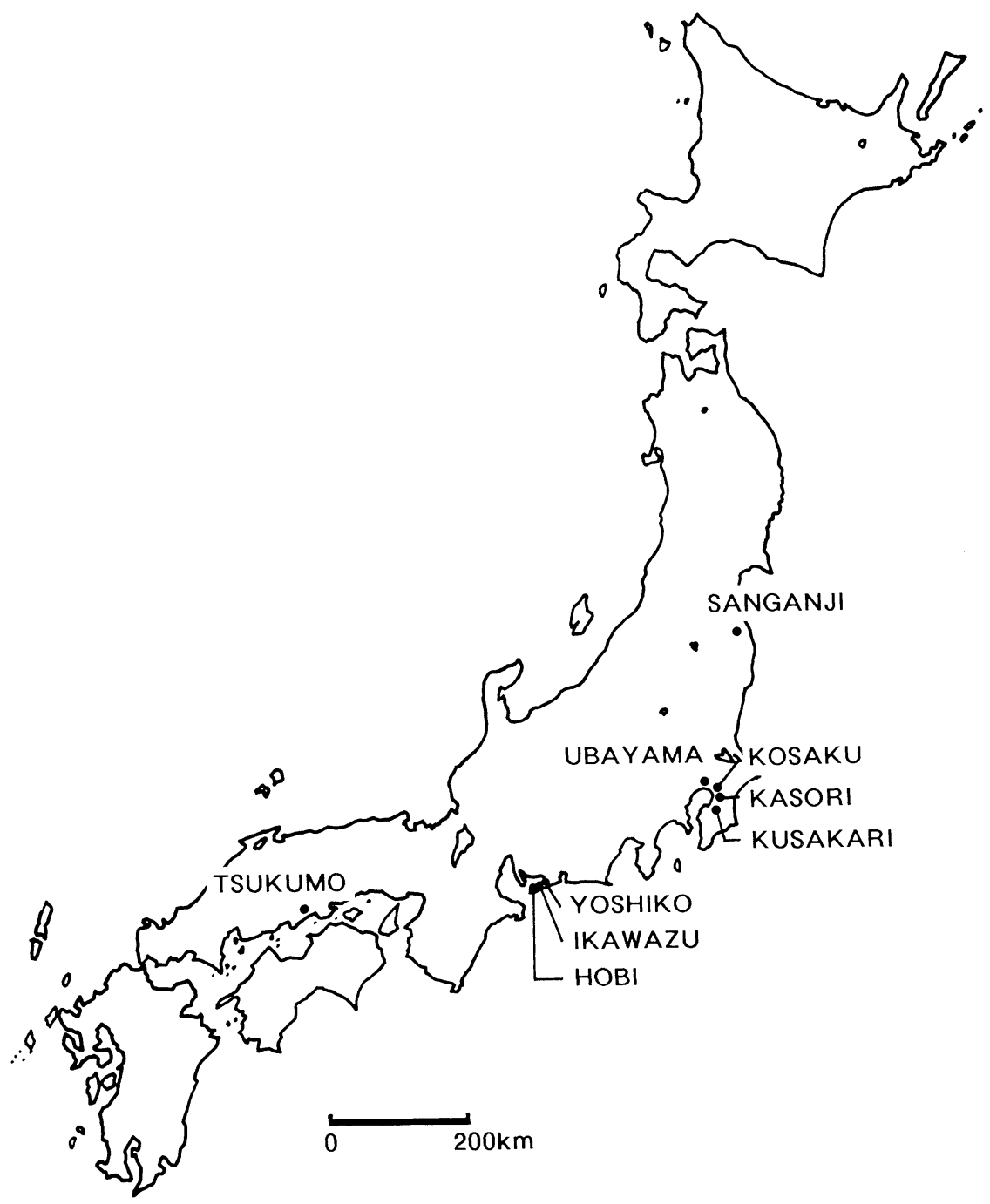

Fig. 1. Locations of the archaeological sites used in this study. 


\section{RESULTS}

The mean values of the 10 linear measurements in each sample and the results of $t$-tests for the differences between Ubayama and the others are shown in Table 1. A nested analysis of variance was carried out in order to analyze the homogeneity or heterogeneity of these measurements (Table 2). The differences between regions are significant at the level of 0.05 in three measurements, i.e., auriculo-bregmatic height, sagittal frontal arc and orbital height. On the other hand, the differences within regions are significant in two measurements barely at the level of 0.1 . Thus, some characters showed regional heterogeneity and were effective for the interregional analysis.

Table 1. Comparisons of mean values and the results of $t$-test ${ }^{1)}$ between Ubayama and other sites

\begin{tabular}{|c|c|c|c|c|c|c|c|}
\hline \multirow[b]{2}{*}{ variables $^{2)}$} & \multicolumn{3}{|c|}{ CHIBA } & \multicolumn{2}{|c|}{ ATSUMI } & \multirow{2}{*}{$\frac{\text { TOHOKU }}{\text { Sanganji }}$} & \multirow{2}{*}{$\frac{\text { CHUGOKU }}{\text { Tsukumo }}$} \\
\hline & Ubayama & Kasori & Kusakari & Yoshiko & Ikawazu & & \\
\hline \multirow[t]{2}{*}{ 1:max. cranial $\mathrm{l}$. } & 183.9 & 183.6 & 180.2 & 183.2 & 182.7 & 181.2 & 185.7 \\
\hline & & & & & & (12) & (20) \\
\hline \multirow[t]{2}{*}{ 8:max. cranial b. } & 146.0 & 143.6 & $139.3 *$ & 144.3 & 146.7 & 144.8 & 145.1 \\
\hline & (22) & (8) & (4) & (36) & (3) & (13) & (21) \\
\hline \multirow{2}{*}{ 9:min. frontal b. } & 97.6 & 98.3 & 97.3 & 97.2 & 95.7 & 100.2 & 96.6 \\
\hline & (24) & (9) & (4) & (37) & (3) & (11) & (21) \\
\hline \multirow{2}{*}{$\begin{array}{l}\text { 20:auriculo- } \\
\text { bregma height }\end{array}$} & 117.0 & 118.2 & 113.8 & 116.9 & 116.4 & 118.7 & $112.7^{* * *}$ \\
\hline & (26) & (9) & (4) & (31) & (3) & (11) & (20) \\
\hline \multirow{2}{*}{$\begin{array}{l}\text { 26:frontal- } \\
\text { sagittal arc }\end{array}$} & 125.6 & 128.8 & 125.5 & 126.1 & 113.0 & 126.8 & 122.1 \\
\hline & (23) & (7) & (4) & $(36)$ & (1) & $(8)$ & $(21)$ \\
\hline \multirow{2}{*}{$\begin{array}{l}\text { 27:parietal- } \\
\text { sagittal arc }\end{array}$} & 128.4 & 129.7 & 126.6 & 130.6 & 137.0 & 129.2 & 129.0 \\
\hline & $(24)$ & (7) & (5) & $(41)$ & $(2)$ & (13) & $(20)$ \\
\hline \multirow{2}{*}{$\begin{array}{l}\text { 43:outer biorbital } \\
\text { breadth }\end{array}$} & 110.3 & 108.1 & 111.3 & 108.2 & 109.0 & 107.8 & 109.0 \\
\hline & (23) & (9) & (3) & $(34)$ & (1) & (4) & (18) \\
\hline \multirow{2}{*}{ 48:upper facial h. } & 66.4 & 68.4 & 68.5 & 64.1 & 68.0 & 66.0 & 68.3 \\
\hline & (15) & (5) & (2) & (15) & (1) & (2) & $(16)$ \\
\hline \multirow{2}{*}{ 51:orbital b. } & 42.1 & 42.5 & 44.0 & 42.4 & 41.5 & 41.3 & 43.4 \\
\hline & (19) & (4) & (1) & (18) & (2) & (3) & (18) \\
\hline \multirow{2}{*}{ 52:orbital h. } & 32.0 & 32.1 & 32.0 & 33.1 & $36.0 *$ & 34.3 & $33.9 *$ \\
\hline & (19) & (6) & (2) & (17) & $(2)$ & (3) & (16) \\
\hline
\end{tabular}

1) Significance level: $* P<0.05$ and $* * P<0.01$.

2) Variable number according to Martin's textbook (Bräuer, 1988).

3) Available sample sizes in parentheses.

From the viewpoint of total cranial morphology assessed by multivariate analysis, however, different aspects of homo- and hetero-geneity were found. When the Mahalanobis' $D^{2}$ between a reference population and a certain sample is tested for statistical significance by means of the bootstrap method, the probability can be used 
Table 2. A nested analysis of variance based on 10 linear measurements. Sites within each region are as follows. Tohoku - Sanganji; Northern Chiba - Ubayama/Kasori/Kusakari; Atsumi Peninsula - Yoshiko/Ikawazu; Chugoku - Tsukumo

\begin{tabular}{|c|c|c|c|c|c|c|c|c|}
\hline \multirow[b]{2}{*}{ variables $^{1)}$} & \multicolumn{3}{|c|}{ between-region } & \multicolumn{3}{|c|}{ within-region } & \multicolumn{2}{|c|}{ error } \\
\hline & d.f. ${ }^{2)}$ & s.s. ${ }^{3)}$ & $F$-value ${ }^{4)}$ & d.f. & s.s. & $F$-value & d.f. & s.s. \\
\hline 1:max. cranial l. & 3 & 166.9 & 1.39 & 3 & 58.8 & 0.49 & 103 & 4121.4 \\
\hline 8:max. cranial b. & 3 & 5.6 & 0.97 & 3 & 180.2 & $2.40 *$ & 100 & 2506.2 \\
\hline 9:min. frontal b. & 3 & 107.3 & 1.92 & 3 & 11.2 & 0.20 & 102 & 1895.2 \\
\hline $\begin{array}{l}\text { 20:auriculo- } \\
\text { bregma height }\end{array}$ & 3 & 279.6 & $6.11^{* *}$ & 3 & 55.4 & 1.21 & 85 & 1943.8 \\
\hline $\begin{array}{l}26 \text { :frontal- } \\
\text { sagittal arc }\end{array}$ & 3 & 269.6 & $2.91 * *$ & 3 & 225.6 & $2.44 *$ & 93 & 2870.1 \\
\hline $\begin{array}{l}\text { 27:parietal- } \\
\text { sagittal arc }\end{array}$ & 3 & 131.5 & 0.99 & 3 & 106.2 & 0.80 & 105 & 4645.4 \\
\hline $\begin{array}{l}\text { 43:outer biorbital } \\
\text { breadth }\end{array}$ & 3 & 51.1 & 1.03 & 3 & 38.1 & 0.77 & 85 & 1403.2 \\
\hline 48:upper facial $\mathrm{h}$. & 3 & 132.5 & $2.53 *$ & 3 & 34.2 & 0.65 & 49 & 854.9 \\
\hline 51:orbital b. & 3 & 19.8 & 1.35 & 3 & 5.1 & 0.35 & 58 & 284.1 \\
\hline 52:orbital h. & 3 & 46.7 & $3.60 * *$ & 3 & 14.9 & 1.15 & 58 & 250.8 \\
\hline
\end{tabular}

1) Variable number according to Martin's textbook (Bräuer, 1988).

2) Degree of freedom.

3) Sum of square.

4) Significance level: $* P<0.10$ and $* * P<0.05$.

as a parameter to illustrate to what degree the target sample differs from the reference population. I therefore investigated the regional homogeneity of Jomon populations in the two districts - northern Chiba and Atsumi Peninsula - by comparing the bootstrap probabilities.

Table 3 shows the Mahalanobis' $D^{2}$ s and the bootstrap probabilities in the case where the two samples, Ubayama and Yoshiko, were used as the reference population. These results are schematically shown in Fig. 2. The sample size is 20 for Ubayama, 7 for Kasori and 4 for Kusakari in northern Chiba. In Atsumi Peninsula, the sample size of Yoshiko is 18, that of Ikawazu is 4 and that of Hobi is 9 .

In the case where Ubayama is used as a reference population (Fig. 2(a)), the heterogeneity of northern Chiba, which is represented by the distances between Ubayama and Kasori and between Ubayama and Kusakari, is nearly comparable to that between Ubayama and two Atsumi Peninsula sites, Ikawazu and Hobi. The distance between Ubayama and Yoshiko is smaller $\left(D^{2}=6.52\right)$ but these two populations should still be considered to be different $(P<0.005)$.

In the case where Yoshiko is used as a reference population (Fig. 2(b)), the distance of Ikawazu stands out rather sharply. But the probability for Ikawazu is 
Table 3. Intra- and inter-regional comparisons of Mahalanobis' $D^{2} \mathrm{~s}$ and bootstrap derived probabilities

(a)

\begin{tabular}{llcc}
\hline $\begin{array}{l}\text { Reference } \\
\text { group }\end{array}$ & $\begin{array}{l}\text { Comparative } \\
\text { group }\end{array}$ & $\begin{array}{l}\text { Mahalanobis' } \\
D^{2}\end{array}$ & $\begin{array}{l}\text { Bootstrap derived } \\
\text { probability }\end{array}$ \\
\hline Ubayama & Kasori & 32.5449 & 0.01 \\
& Kusakari & 75.3061 & 0.015 \\
& & & \\
& Yoshiko & 6.51989 & $<0.005$ \\
Ubayama & Ikawazu & 68.6652 & 0.01 \\
& Hobi & 22.3733 & 0.015 \\
& Sanganji & 9.05473 & 0.04 \\
& Tsukumo & 12.6543 & 0.015 \\
\hline
\end{tabular}

(b)

\begin{tabular}{llcc}
\hline $\begin{array}{l}\text { Reference } \\
\text { group }\end{array}$ & $\begin{array}{l}\text { Comparative } \\
\text { group }\end{array}$ & $\begin{array}{l}\text { Mahalanobis' } \\
D^{2}\end{array}$ & $\begin{array}{l}\text { Bootstrap derived } \\
\text { probability }\end{array}$ \\
\hline \multirow{2}{*}{ Yoshiko } & Ikawazu & 184.786 & $<0.005$ \\
& Hobi & 20.9341 & 0.32 \\
& & & \\
& Ubayama & 15.3472 & $<0.005$ \\
Koshiko & Kasori & 4.46041 & 0.425 \\
& Kusakari & 26.7128 & 0.04 \\
& Sanganji & 29.2218 & 0.175 \\
& Tsukumo & 40.4577 & $<0.005$ \\
\hline
\end{tabular}

equal to those between Yoshiko and Ubayama and between Yoshiko and Tsukumo, though these lowest probabilities are under the limit of the bootstrap probability $(1 / 200)$. The probability for Hobi $(P=0.32)$ is intermediate between that for Sanganji $(P=0.175)$ and that for Kasori $(P=0.425)$. The heterogeneity within the Atsumi Peninsula area appears thus to be comparable to the differences between these geographical regions.

In summary, not only did metric characters of individuals show no clear homogeneity in the two geographical regions - northern Chiba and Atsumi Peninsula - the heterogeneity within the respective regions was quite comparable to the differences between regions.

I also calculated distances between groups based on the non-metric characters (Table 4) as described in part I (Kondo, 1993). While the results from the distance matrix (Table 5) and the two-dimensional plot (Fig. 3) are not completely comparable with the bootstrap results because the sites used in the analysis were different, it is plain that the distances within the respective regions (Ubayama Kasori - Kusakari - Kosaku and Hobi - Ikawazu) are, again, comparable to those 
(a)

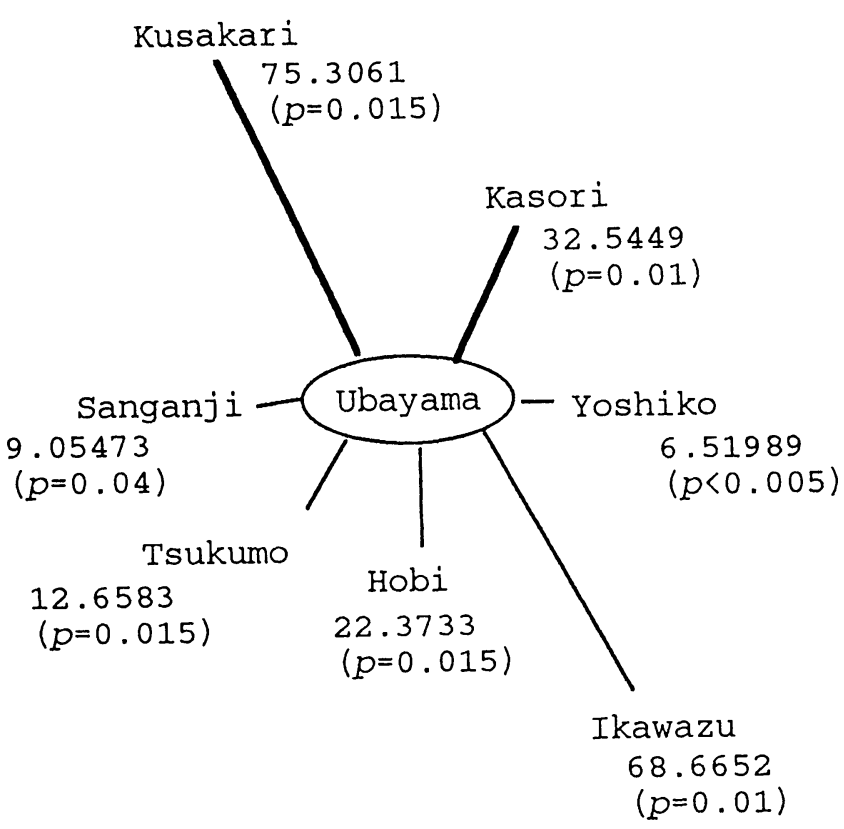

(b)

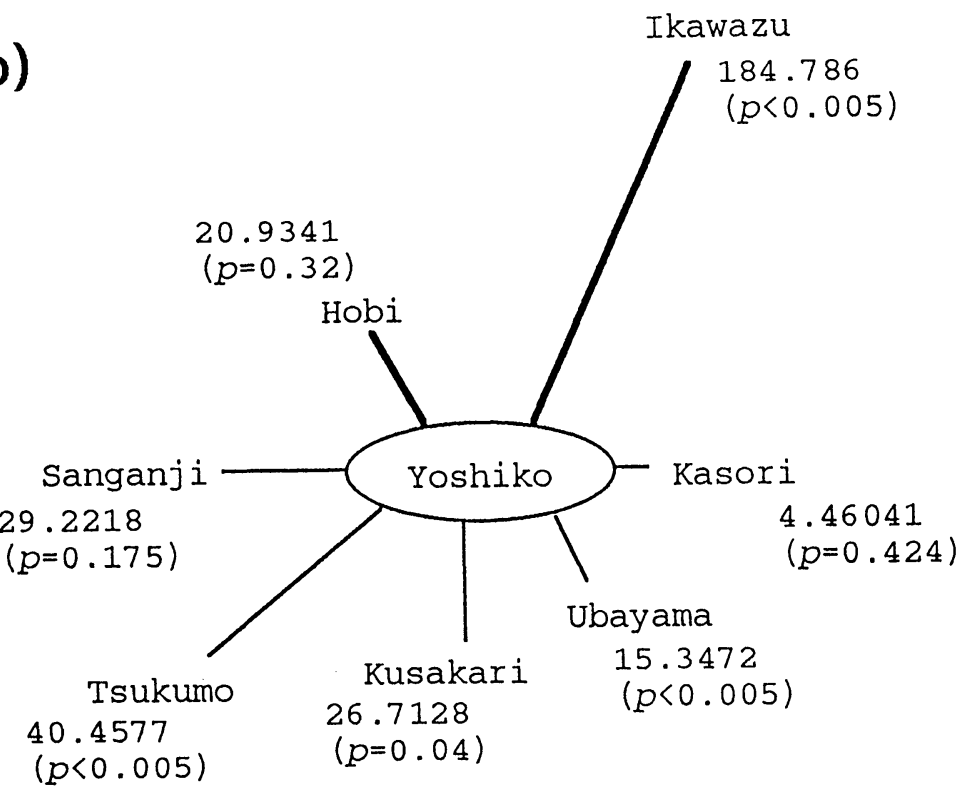

Fig. 2. Schematic representation of the intra- and inter-regional variation constructed from Table 3. Reference populations are Ubayama in (a) and Yoshiko in (b). 
Table 4. Non-metric characters used for calculation of Mahalanobis' $D^{2}$ equivalent

\begin{tabular}{rll}
\hline & Non-metric characters \\
\hline 2 & nending frontal process \\
3 & zygomaxillary tubercle \\
4 & marginal tubercle \\
5 & metopism \\
6 & supraorbital nerve groove \\
7 & supraorbital foramen \\
8 & biasteric suture \\
9 & hypoglossal canal bridging \\
10 & transverse zygomatic suture \\
11 & mylohyoid bridging \\
12 & mandibular torus \\
13 & sagittal groove left \\
\hline
\end{tabular}

Table 5. Distance matrix based on 13 non-metric characters

\begin{tabular}{llllllll}
\hline Kasori & .250829 & & & & & \\
Kusakari & .433511 & .502218 & & & & \\
Kosaku & .387570 & .318684 & .480928 & & & \\
Sanganji & .443760 & .570024 & .217844 & .426335 & & \\
Ikawazu & .302413 & .312979 & .423622 & .269241 & .445616 & \\
Hobi & .295642 & .734548 & .450573 & .635885 & .523817 & .427397 \\
\hline & Ubayama & Kasori & Kusakari & Kosaku & Sanganji & Ikawazu \\
\hline
\end{tabular}

between geographical regions (Ubayama - Sanganji and Ubayama - Hobi).

There were some disparities between the metric bootstrap-derived results and the non-metric ones; for example, the difference between Ubayama and Sanganji is most distinct in the non-metric analysis, while the difference between Ubayama and Sanganji was smaller than that between Ubayama and Kasori in the bootstrap results. Descriptive characters may be of great use in distinguishing between sub-groups actually existing within populations which have so far been defined as unique, especially by metric characters. 


\section{dim2}

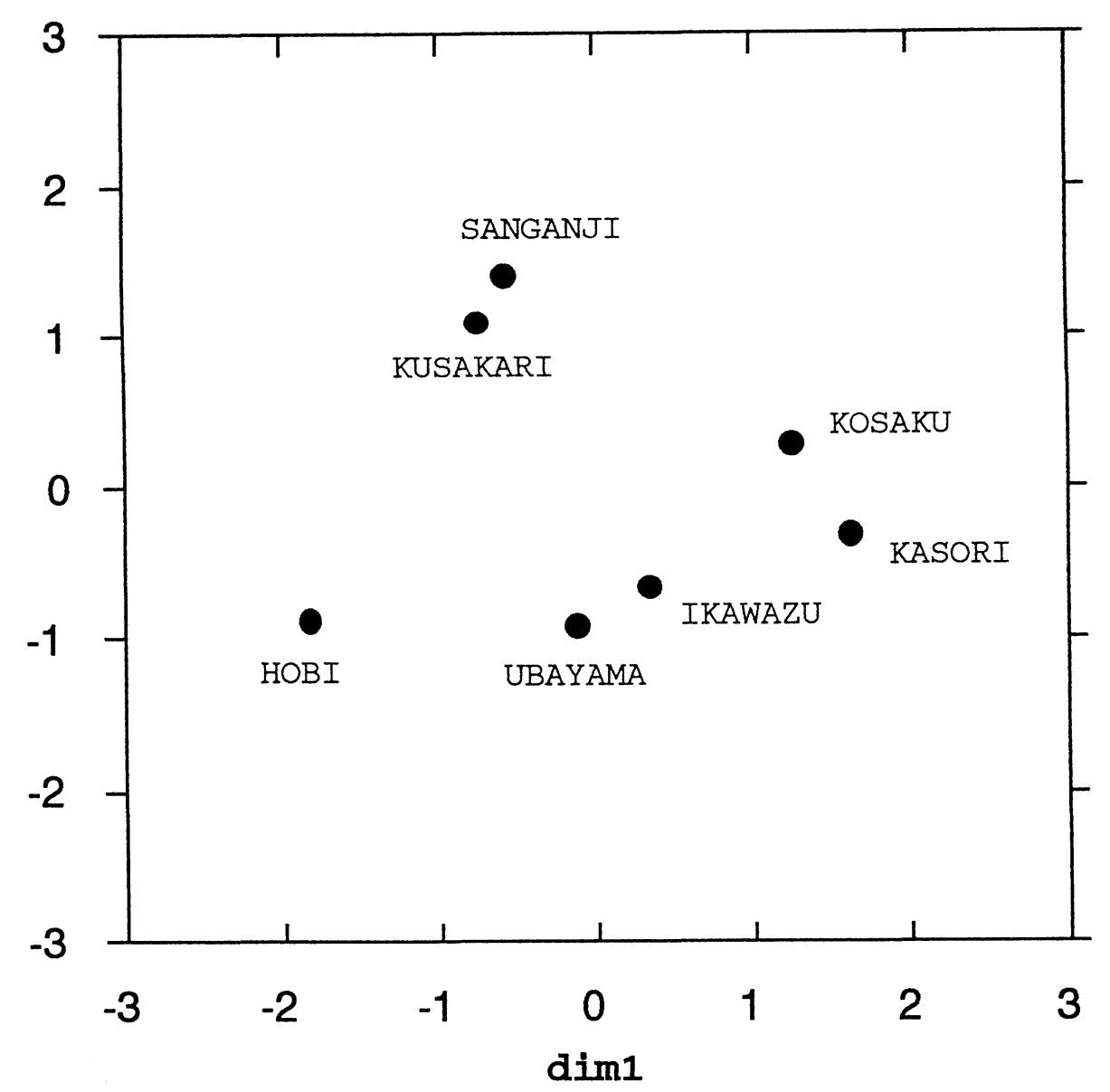

Fig. 3. Two-dimensional representation of the distance matrix in Table 5, based on 13 non-metric characters. Stress $=0.172$

\section{DISCUSSION}

The above results provide a basis for discussion on the issue of regional homogeneity or heterogeneity of Jomon crania. The regional heterogeneity within the northern Chiba cranial series was shown to be less than that for the Atsumi Peninsula crania, but we still cannot regard the northern Chiba population as homogeneous because the bootstrap probabilities showed significant differences between sites. I also found that this heterogeneity within the northern Chiba was 
comparable in degree to that between geographical regions. The lower homogeneity among the Atsumi Peninsula sites stemmed mainly from the great divergence of the Ikawazu sample from the others of the region. Mahalanobis' $D^{2} \mathrm{~s}$ are probably effected by small sample sizes, such as that from Ikawazu, which leads to a relatively long distance in results, but the bootstrap-derived probabilities are not affected insofar as the shape of a null distribution is presumed to be the same as that of a reference population. Although some would dispute this presumption, it does allow standards of comparison for the analysis of small samples.

The demonstrated heterogeneity in each of the two geographical regions implies that the comparative studies lumping the samples from various archeological sites may not be valid. The differences between two archeological sites within a geographical region are sometimes greater than those between regions.

Uchida (1985) showed that Tsukumo was much different from other groups, based on the following variables: maximum cranial length, maximum frontal breadth, sagittal frontal arc, upper facial height, cranial length-height index and sagittal frontal index. She noted that the distinction between Tsukumo and the other samples compared was due to the height of cranial vault and the degree of frontal curvature. In order to enable comparisons with Uchida's results, the six linear variables - maximum cranial length, maximum frontal breadth, basion-bregma height, sagittal frontal arc, nasion-bregma chord and upper facial height — on which Uchida's analysis was based were used here.

The Mahalanobis' $D^{2} \mathrm{~s}$ of my calculation are given in Table 6a, and the Penrose's shape distances quoted from Uchida (1985) in Table 6b. The two dimensional plots

Table 6. Mahalanobis' $D^{2}$ s based on 6 variables (a), and Penrose's shape distances cited from Uchida (1985) (b)

(a)

\begin{tabular}{llllll}
\hline Kasori & 2.1577 & & & & \\
Kusakari & 1.7617 & 1.6592 & & & \\
Sanganji & 2.0541 & 1.2679 & 2.1508 & & \\
Yoshiko & 2.3848 & 1.6767 & 2.3138 & 1.1665 & \multirow{2}{*}{3.2319} \\
Tsukumo & 3.8839 & 2.2283 & 3.6148 & 3.0383 & Yoshiko \\
\hline & Ubayama & Kasori & Kusakari & Sanganji & Yon \\
\hline
\end{tabular}

(b)

\begin{tabular}{lllll}
\hline Kasori & 0.15 & & & \\
Sanganji & 0.08 & 0.10 & & \\
Yoshiko & 0.16 & 0.13 & 0.22 & \\
Tsukumo & 0.60 & 0.48 & 0.57 & 0.62 \\
\hline & Ubayama & Kasori & Sanganji & Yoshiko \\
\hline
\end{tabular}


are shown in Figs. 4 and 5. In my analysis (Fig. 4), the peculiarity of Tsukumo is not as remarkable as reported by Uchida. The peculiarity of Tsukumo in her analysis may have resulted from her including two indices into variables, which showed clear distinction between Tsukumo and others. In comparison with my result, the distance between Ubayama and Sanganji in Uchida's result is very small (Fig. 5). This may reflect oversimplification by the use of Penrose's distance or the relatively high stress $(=0.234)$ of the multi-dimensional scaling, resulting in a poor graphic situation (Kendall, 1980).

\section{$\operatorname{dim} 2$}

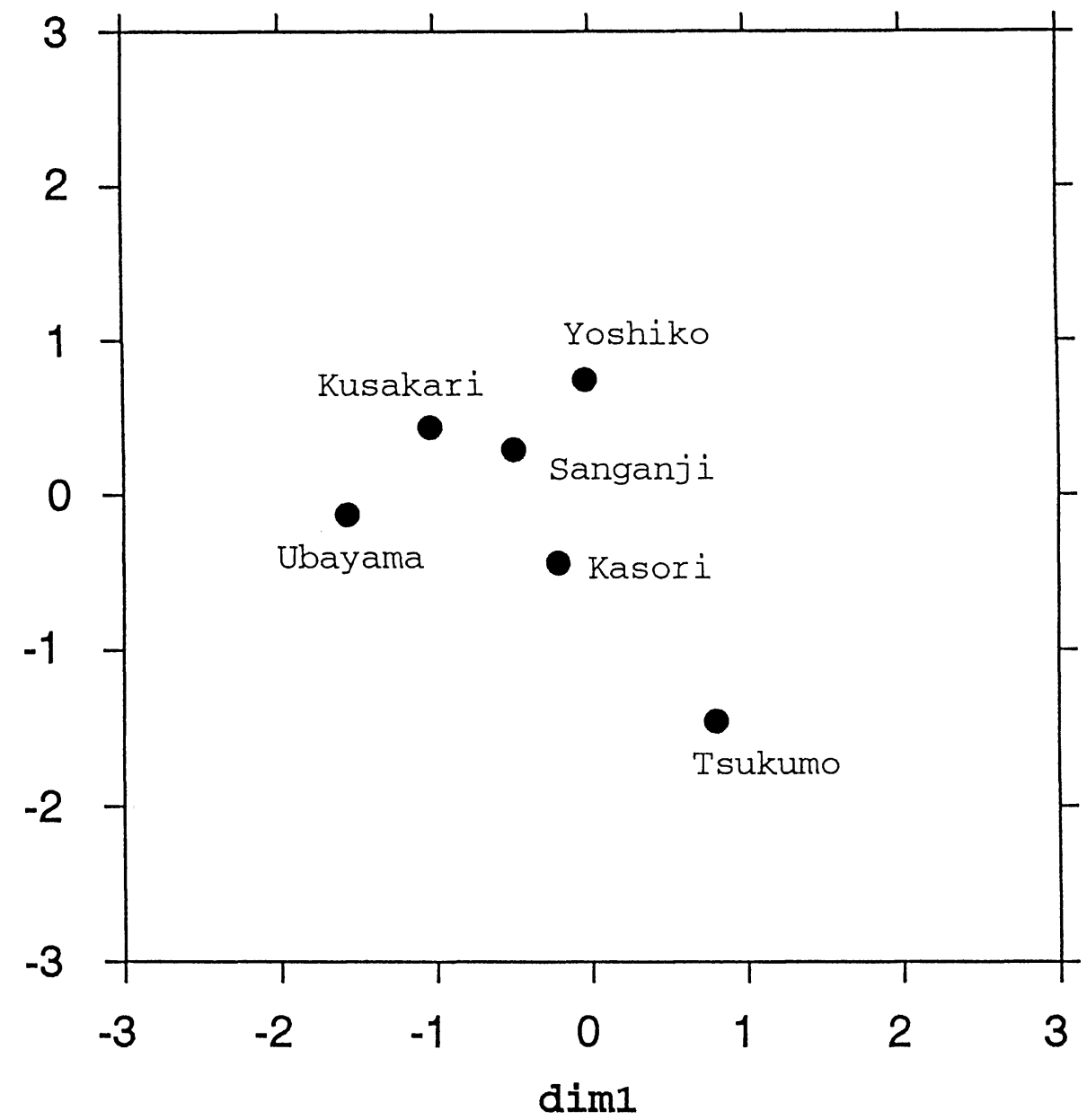

Fig. 4. Two-dimensional representation of the Mahalanobis' $D^{2}$ matrix in Table $6($ a). Stress $=0.131$ 
Dodo asserted a close similarity between Tohoku and Kanto Jomon crania (Dodo, 1982). He found regional differences between Tohoku and western Honshu Jomon in some cranial measurements and indices using a combined population consisting of Tsukumo and Yoshiko for the western Honshu Jomon. These similarities and distinctions are obscured, however, if the intra-regional heterogeneity for the Tohoku region is taken into account, this is actually much greater than the difference between Tohoku and other geographical regions.

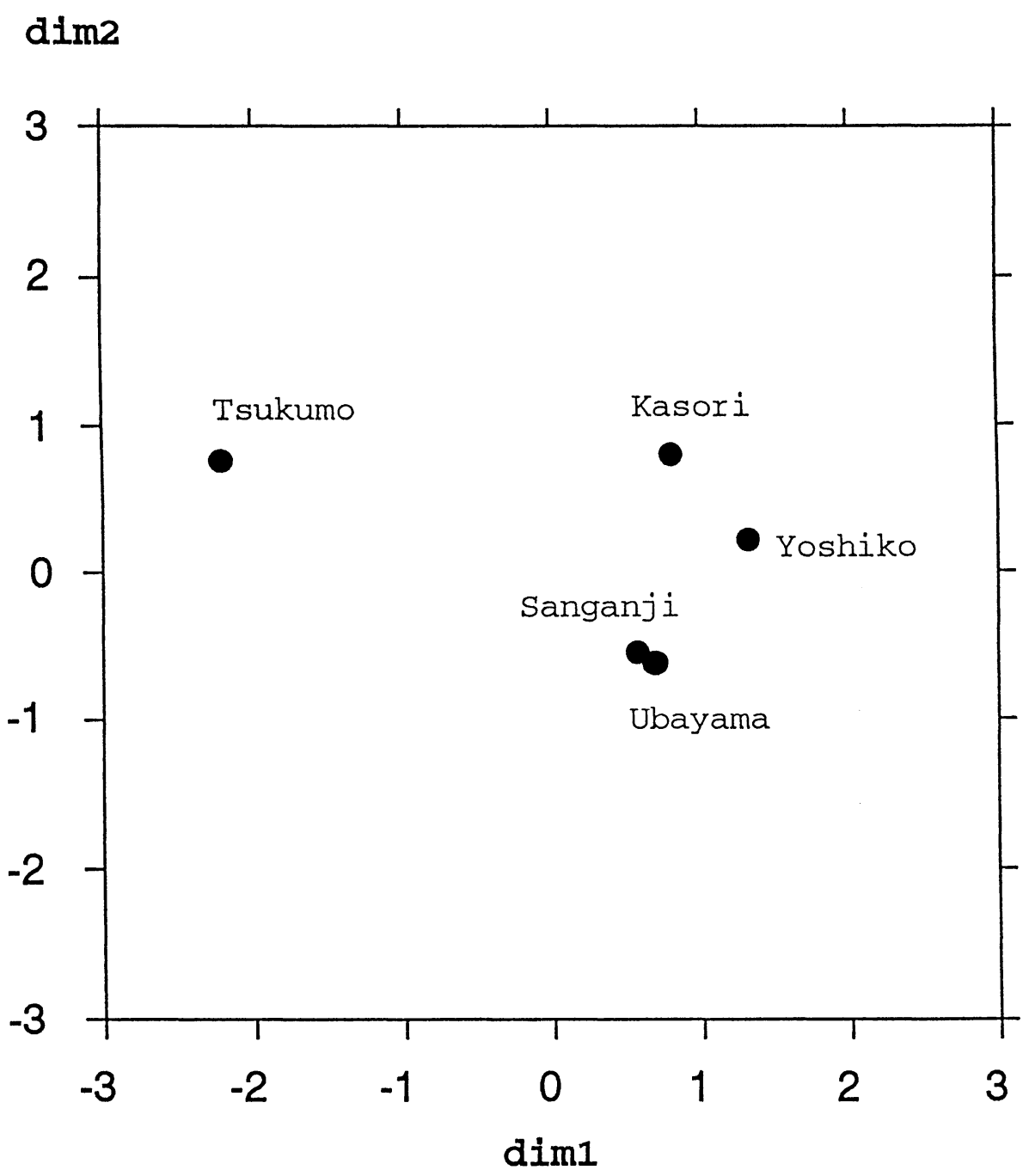

Fig. 5. Two-dimensional representation of the Penrose's distance matrix in Table 6(b) cited from Uchida (1985). Stress $=0.234$ 
Yamaguchi (1982) also used a combined Jomon population from southern Kanto. In his study, the peculiarity of Tsukumo is much smaller than indicated by Uchida. This is likely due to the difference in the author's choice of variables. Nonetheless, the findings from site specific samples presented here (Fig. 2), examined by the unique criteria of Mahalanobis' distance and the bootstrap probabilities, cast some doubt on Uchida's conclusion of the peculiarity of Tsukumo from the Ubayama and Yoshiko populations.

The results of this study indicate caution when lumping or dividing samples into some regional categories. Previous authors' results regarding inter-regional differences or similarities of Jomon populations may be modified in consideration of intra-regional variation.

Yamaguchi and Dodo reported a regional cline of Jomon crania in some characters in previous papers (Yamaguchi, 1981, 1982; Dodo, 1982), but no differences represented such a cline were found in this multivariate analysis at least between two regions, northern Chiba and Atsumi Peninsula. A wider choice of variables including not only metric but also descriptive characters will be needed to confirm this cline. More information about samples as regards their archeological sites will enable us to understand the spatial and temporal aspects of Jomon crania.

\section{CONCLUSION}

I investigated intra- and inter-regional homogeneity or heterogeneity of Jomon skulls using bootstrap probabilities. These were expected to prove an interesting parameter of morphological similarity between sites, but in two geographical regions - northern Chiba and Atsumi Peninsula - so little homogeneity was found that the regions could not be accepted as a single morphological unit; moreover, the two regions showed much internal heterogeneity, each with its unique pattern. This intra-regional heterogeneity was almost comparable to the inter-regional one.

The assumption of "regional characteristics" according to a composite from various samples collected throughout the region in question has always been approximate, at best, except for a few, remarkable populations whose isolation from others was "proven" for the historical period under examination. Improved methods of analysis should not be neglected in investigation of site-to-site variation prior to new assertions about morphological distances between adjacent geographical regions.

\section{ACKNOWLEDGEMENTS}

I would like to thank the following persons for permission to study the Jomon crania in their charge: Drs. H. Suzuki and T. Akazawa of the University Museum, the University of Tokyo; Dr. B. Yamaguchi of the National Science Museum, Tokyo; Dr. I. Morimoto of the Department of Anatomy, St. Marianna University 
School of Medicine; Ms. K. Shirai, the Cultural Properties Center of Chiba Prefecture, Chiharadai Branch Office. I wish to express my gratitude to Dr. Y. Mizoguchi of the National Science Museum for some hints and helpful advice on statistical analyses. I am also greatly indebted to Drs. B. Endo and G. Suwa of the Department of Anthropology, the University of Tokyo and Dr. Y. Dodo of the Department of Anatomy, Sapporo Medical University, for many suggestions and corrections of this paper.

\section{REFERENCES}

Bräuer, G. (1988) Osteometry. In Anthropologie (Martin, R., and Knussman, K., ed.), Gustav Fischer, Stuttgart, pp. 160-232.

Diaconis, P., and Efron, B. (1983) Computer-intensive methods in statistics. Scientific American, 248(5), 96-108.

Dodo, Y. (1982) A metrical analysis of Jomon crania from the Tohoku district. J. Anthrop. Soc. Nippon 90 (suppl.), 119-128. (In Japanese with English summary)

Dodo, Y. (1986) Metrical and non-metrical analysis of Jomon crania from eastern Japan. In Prehistoric Hunter-gatherers in Japan (Akazawa, T., and Aikens, C.M., ed.), Bull. Univ. Mus. Univ. Tokyo 27, pp. 137-161.

Efron, B. (1982) The Jacknife, the Bootstrap and Other Resampling Plans, SIAM, Philadelphia.

Efron, B., and Gong, G. (1983) A leisurely look at the bootstrap, the jacknife, and cross-validation. American Statistician 37(1), 36-49.

Hanihara, K., Baba, H., Dodo, Y., Matsumura, H., Suzuki, T., and Uchida, A. (1988) Human skeletal remains from Sanganji shell-mounds. In Sanganji Shell-mounds, Bull. Fukushima Prefecture Museum 17, pp. 413-494. (In Japanese)

Hiramoto, K., and Mizoguchi, Y. (1986) Human skeletal remains of Kusakari site. In Chiharadai New Town 3, Cultural Properties Center of Chiba Prefecture, pp. 797-861.

Ikeda, J. (1985) Jomon people in the mountain and coastal region. In Nihonshi-no Reimei, Rokkou Shuppan, Tokyo, pp. 29-56. (In Japanese)

Kendall, M. (1980) Multivariate Analysis, 2nd Ed., Charles Griffin, England.

Kintaka, K. (1928) Anthropologische Untersuchungen über das Skelett der Yoshiko-Steinzeitmenschen. 1. Der Schädel. J. Anthrop. Soc. Tokyo 43 (suppl.), 497-736. (In Japanese with German tables)

Kiyono, K., and Miyamoto, H. (1926) Anthropologische Untersuchungen über das Skelett der Tsukumo-Steinzeitmenschen. 2 Der Schädel. J. Anthrop. Soc. Tokyo 41, 95-140, 151-208. (In Japanese with German tables)

Kobayashi, K. (1966) Trend in the Length of Life Based on Human Skeletons from Prehistoric to Modern Times in Japan. D. Sc. thesis, Department of Anthropology, University of Tokyo.

Kondo, O. (1993) Skulls of Ubayama shell-mounds. I. Morphological description and univariate comparison. Anthrop. Sci. 101, 307-331.

Konigsberg, L.W. (1990) Analysis of prehistoric biological variation under a model of isolation by geographic and temporal distance. Hum. Biol. 62(1), 49-70.

Lele, S., and Richtsmeier, J.T. (1992) On comparing biological shapes: Detection of influential landmarks. Am. J. Phys. Anthropol. 87, 49-65.

Mizoguchi, Y. (1993) Overall associations between dental size and foodstuff intakes in modern human populations. Homo 44(1), 37-73. 
Mizoguchi, Y. (1985) Shovelling: A statistical analysis of its morphology. Bull. Univ. Mus. Univ. Tokyo 26.

Morimoto, I., Yoshida, T., and Kudo, H. (1983) Descriptions of the excavated human skeletons. In Kosaku Kaizuka II, Funabashi-shi Isekichosakai Kosaku Kaizuka Chosadan, pp. 86-100.

Ogata, T. (1967) A preliminary discussion of the human skeletons from cavesites. In The Cave Sites in Japan (Nihon no Douketsu Iseki), Heibon-sha, Tokyo, pp. 382-423. (In Japanese)

Ogata, T. (1969) Observations of the excavated human skeletons. In Kasori Kaizuka I (Kasori Kaizuka Chousadan ed.), Chuokoron Bijutsu Shuppan, Tokyo, pp. 49-52. (In Japanese)

Ogata, T. (1973) A preliminary discussion of the Jomon skeletal morphology. Dorumen 1, 22-33. (In Japanese)

Ogata, T. (1981) Human skeletal remains of the Jomon period. In Jinruigaku Koza (Anthrop.) 5, Yuzankaku Shuppan, Tokyo, pp. 27-55. (In Japanese)

Suzuki, H., Kimura, T., and Baba, H. (1968) Human skeletal remains excavated from the Kasori shell mounds. In Kasori Minami-Kaizuka II. (Kasori-Kaizuka Chosadan, ed.), Chuokoron Bijutsu Shuppan, Tokyo, pp. 206-225. (In Japanese)

Suzuki, H. (1969) Microevolutional changes in the Japanese population from the prehistoric age to the present-day. J. Fac. Sci. Univ. Tokyo, Sec. 5 3, Part 4, 279-308.

Suzuki, H., Endo, B., and Terasawa, T. (1972) Human skeletal remains of Ikawazu shell mounds, Aichi Prefecture. In A Report on the Excavation of Ikawazu Shell Mounds, pp. 171-179. (In Japanese)

Uchida, A. (1985) Regional Variation of Jomon Cranial Series. M. Sc. thesis, Department of Anthropology, University of Tokyo. (In Japanese)

Yamaguchi, B (1981) Human skeletal remains of the Jomon period. Kikanjinruigaku 12-1, 38-50. (In Japanese)

Yamaguchi, B. (1982) A review of the osteological characteristics of the Jomon population in prehistoric Japan. J. Anthrop. Soc. Nippon 90 (suppl.), 77-90.

Yasuda, S., and Umino, M. (1977) Social Statistics (Shakai Toukeigaku), 2nd Ed., Maruzen, Tokyo. (In Japanese) 